\title{
A INVENÇÃO DA HETERONORMATIVIDADE: UM ROMANCE AUTOBIOGRÁFICO
}

\section{LA INVENCIÓN DE LA HETERONORMATIVIDAD: UNA NOVELA AUTOBIOGRÁFICA}

\section{Rosana Cristina Zanelatto Santos ${ }^{211}$}

RESUMO: A naturalização da heterossexualidade via heteronormatividade alimenta uma lógica de desumanização do sujeito, por meio de um processo que se inicia pelo corpo, estendendo-se pela linguagem e pelas relações de gênero, sociais, políticas e culturais, o que torna nua a identidade desse sujeito. Ele passa então a ser (re)conhecido por sua existência física/material e não por aquilo que ele quer ser e por aquilo que ele quer que o mundo compreenda nele/dele. Propõe-se a possibilidade de compreensão da heteronormatividade como uma invenção retórica que contribui significativamente para a encenação e a fixação de uma aparência de naturalização, de centralidade e de necessidade acerca das diferenças de gênero, tendo como reforço ações como a transfobia e a homofobia. Para dialogar com essa possibilidade, elegeu-se o romance autobiográfico de João W. Nery (2011) Viagem solitária: memórias de um transexual trinta anos depois.

Palavras-chave: Heteronormatividade; invenção; retórica; literatura brasileira contemporânea.

RESUMEN: La naturalización de la heterosexualidad por la heteronormatividad alimenta una lógica de deshumanización del sujeto, mediante un proceso que comienza en el cuerpo, extendiéndose por el lenguaje y el género, las relaciones sociales, políticas y culturales, lo que desnuda la identidad de este sujeto. Entonces, el sujeto se vuelve (re)conocido por su existencia física/material y no por lo que quiere ser y lo que quiere que el mundo entienda en él. La posibilidad de comprender la heteronormatividad se propone como una invención retórica que

211 Doutora em Letras pela USP. Docente na UFMS - Campo Grande. Docente permanente do PPGEL-UFMS e do PPGL-UFMS. PQ-CNPq. Pesquisadora da FUNDECT-MS. 
contribuye significativamente a la promulgación y al establecimiento de una apariencia de naturalización, centralidad y necesidad sobre las diferencias de género, reforzando acciones como la transfobia y la homofobia. Para dialogar con esta posibilidad, se eligió la novela autobiográfica de João W. Nery (2011) Viagem solitária: memorias de um transexual trinta anos depois.

Palabras-clave: Heteronormatividad; invención; retórica; literatura brasileña contemporánea.

Como a melhor defesa é o ataque, resolvi passar de inquirido a inquiridor. Fiz algumas perguntas sobre a sua vida pessoal, a fim de conhecer melhor aquele tipo de gente. A figura misturada de homem e mulher me fascinava. Não conseguia entender bem. Disparei então

a pergunta que mais me interessava: - Se você pudesse, gostaria de ser mulher? - Nunca! Adoro ser veado! Não gosto de ser homem nem mulher, mas ve-a-do. Deu para entender?

Aquilo me intrigou ainda mais. Era, realmente, outro gênero! (João W. Nery) $)^{212}$

\section{Inventando a heteronormatividade}

Em Retórica, o percurso da invenção abrange a primeira etapa de um processo de fixação e de afirmação de lugares não somente linguísticos, de fala, de oralização, mas sobretudo de práticas que passarão a compor o constructo humano em suas várias facetas - políticas, sociais e culturais.

A invenção é construída a partir de evidências e de aparências que poderão preparar o público/a assistência para a boa recepção/o convencimento acerca de algo, caracterizando-se pela busca/pela pesquisa tanto do que deseja o ser humano quanto do que se deseja que o ser humano queira. Por força do tempo e da tradição, uma invenção retórica se torna, ela própria, modelo para invenções subsequentes. Aqueles nas

${ }^{212}$ (2011, p. 25) 
A invenção da heteronormatividade: um romance autobiográfico | 485

mãos de quem está o poder linguístico, político (não necessariamente partidário), socioeconômico e cultural fundam uma invenção, passando a usá-la como instrumento persuasivo, a fim de dissimular o processo manipulativo de construção das normas em sociedade.

Contemporaneamente, em razão do reconhecimento e da admissão das diferentes orientações de gênero, estamos diante de um vocábulo cuja presença pode ser relativamente nova na língua portuguesa, porém tem sua construção engendrada há séculos; referimo-nos aqui à heteronormatividade. Quando, por exemplo, em situações cotidianas ou referendadas institucionalmente, alguém diz sobre a "grande divulgação pela mídia da homossexualidade" ou "da valorização exacerbada da ideologia de gênero", como se isso fosse uma propaganda ou um convite ao desregramento, demonstra, ou o desconhecimento, ou uma atitude dissimulada que contribui para o reforço de uma construção discursiva que demanda a busca por uma homogeneidade que não existe e que não é benfazeja para a sociedade.

A heteronormatividade encena, então, uma ideia/uma aparência de naturalização, de centralidade e de necessidade de distinção entre normais e não-normais que acaba por violentar, punir e matar, negando ao sujeito o direito a ser (humano) e criando formas de ocultamento e de silenciamento que dissimulam a violência no trato das questões de gênero.

\section{Em torno da invenção heteronormativa: um romance autobiográfico}

Em face da problematização das diferenças de gênero, estamos diante de um vocábulo cuja construção de significado tem sido engendrada há séculos, a heteronormatividade. $\mathrm{O}$ conceito foi cunhado em 1991 por Michael Warner, dispondo que:

enquanto na heterossexualidade compulsória todas as pessoas devem ser heterossexuais para serem consideradas normais, na heteronormatividade todas devem organizar suas vidas conforme o modelo heterossexual, tenham elas práticas sexuais heterossexuais ou não. Com isso entendemos que a heteronormatividade não é apenas uma orientação sexual, mas um modelo político que organiza nossas vidas. (COLLING, 2015, p. 24)

Todo "modelo político" é organizado em torno de uma lógica criada a partir não necessariamente do lógos, mas sobretudo da relação 
circular entre o éthos e o páthos. Veremos, mais adiante, como esses três elementos dialogam na composição da unidade retórica "heteronormatividade".

Em artigo publicado no Brasil em 2001, David W. Foster faz referência aos estudos sobre o homoerotismo na literatura latinoamericana como um influxo das reivindicações por direitos pelos movimentos lesbo-gays. A heteronormatividade também acaba sendo pauta de discussões correlatas. Foster (2001, p. 49) assim se pronuncia sobre ela:

Por heteronormatividad se entiende la urgencia imperativa de ser heterosexual y de abogar en todo momento y a toda costa por la primacía de lo heterosexual (entediéndose lo que entiendere por este término).

A urgência referida por Foster reside tanto na lógica do modelo político (como sugerido por Colling, 2015) quanto nos substratos que sustentam uma mentalidade e uma produção cultural reforçadas pela primazia dada à heteronormatividade por instituições como as religiões neopentecostais, por exemplo, com seu poder de manipulação de setores significativos das populações da América Latina. Por outro lado, é também na cultura, especialmente, na arte, que se questiona a legitimidade e a preponderância da heteronormatividade em meio à multiplicidade de modos de os sujeitos se relacionarem socialmente, e as relações sociais passam pelos corpos dos sujeitos. Sobre o corpo, Foster (2001, p. 51) problematiza:

El cuerpo no es un dado y, por ello, la referencia al cuerpo no es un proceso categórico. Sin embargo, un proyecto que conjugue propuestas ideológicas ya hegemónicas sobre el cuerpo con otras perspectivas, siempre cambiantes y multifacéticas, de la corporalidad, se convierte en una dimensión fundamental de la confrontación con cuestionables universales de un cuerpo que se supone viene ya dado.

Esse aparente dissenso entre o corpo e as corporalidades nos levou a pensar em texto literário lido há algum tempo. Trata-se do romance 
A invenção da heteronormatividade: um romance autobiográfico | 487 autobiográfico $^{213}$ Viagem solitária: memórias de um transexual trinta anos depois, de João W. Nery (2011).

Ítalo Damasceno (2018), por ocasião da morte de Nery, em 2018, assim se refere a ele:

Esta carta é porque tá difícil escrever um necrológio hoje eu era doido pra usar essa palavra, portanto, agradeço a oportunidade. Você morreu no dia 26 [de outubro] e eu não consigo fazer apenas um texto que relembre sua jornada. Agora eu preciso de um amigo. Alguém perto de mim o suficiente, para me lembrar: ainda não desaparecemos.

Você me entende e, por isso, colocou o nome da sua autobiografia de Viagem Solitária. Num momento como este, a sensação é de abandono completo. Não sei nem se dá para comparar como a gente se sente agora com a forma que você se sentiu ao fazer aquela cirurgia [de redesignação sexual] em 1977, em plena ditadura militar, como todos os textos sobre sua morte fizeram questão de frisar.

Viagem solitária acompanha a formação do sujeito João W. Nery, ao modo de um Bildungsroman, indicando um processo de reinvenção

213 Se em geral se apresenta o texto de Nery como “autobiografia”, decidimos inscrevê-lo, também, no gênero "romance", considerando sua disposição narrativa e que o narrador está nos relatando sua "viagem”. No ensaio El viaje y su relato, Todorov (1993, p. 99), perguntando-se sobre o que o leitor contemporâneo espera de um relato de viagem, escreve: "[...] relato, es decir narración personal y no descripción objetiva; pero también viaje, un marco, pues, y unas circunstancias exteriores al sujeto. Si sólo figura en su lugar uno de los dos ingredientes, nos salimos del género en cuestión para meternos en otro. [...] Pero también hay una segunda característica del género, que la denominación no retiene, y que es igualmente importante: la localización de las experiencias contadas por los relatos en el tiempo y en el espacio". Esclarecemos, ainda, que não discutiremos as rubricas "autobiografia" e "autobiográfico" neste texto, posto que nosso interesse, neste lugar, é problematizar como a heteronormatividade pode se constituir como norma social e cultural, com ares universais e inquestionáveis, a partir de sua constituição retórica. 
cultural e de gênero permeado por valores previamente estabelecidos e difíceis de serem destecidos, especialmente quando considerados historicamente: o Brasil da década de 1970, em meio à ditadura militar.

$\mathrm{Na}$ Introdução ao texto de Nery (2011, p. 13), intitulado "Corpo estranho", Milos Kaiser escreve: ${ }^{214}$

Eu devia ter uns 7, 8 anos. Tinha achado muito estranho aquele homem com várias cicatrizes no peito, amigo dos meus pais, que tentava puxar papo comigo na praia.

- Mãe, não gostei do João. Ele é esquisito.

[...] - Filho, o João nasceu mulher e virou homem.

Meu mundo caiu. Descobrir que a Vovó Mafalda (apresentadora de programa infantil do canal SBT, interpretado por Valentino Guzzo) era homem já havia sido traumático o suficiente. Eu havia conhecido um caso real, na minha frente, com a transformação marcada na pele, e não por uma fantasia.

A narração da recordação do menino confronta dois universos: o da realidade empírica - com a revelação de que João já fora mulher - e o da realidade imaginativa - com a descoberta de que a Vovó Mafalda era um homem fantasiado de mulher -, ambas criadas a partir de um índice/um indício comum: o da unidade. A aparência de unidade (binária) dos gêneros, dada pelo recurso à sua repetição linguística e/ou imagética ${ }^{215}$, acaba por obscurecer as múltiplas possibilidades de ser (humano) no mundo. Se Valentino podia tirar a fantasia de Vovó Mafalda a qualquer instante, João tivera que passar por muito sofrimento - que deixou marcas em sua vida, não somente as cicatrizes no peito para se despir de Joana, nascida em 1950 no Rio de Janeiro.

${ }^{214}$ Nery informa seu leitor de que o texto de Kaiser foi publicado primeiramente como entrevista na revista Trip de dezembro de 2009.

${ }^{215}$ Foster (2001, p. 52) escreve sobre a importância do papel da "[...] elocuencia retórica de un proyecto cultural" para a imposição da heteronormatividade como norma. 
A invenção da heteronormatividade: um romance autobiográfico | 489

Outros recursos possíveis para o reforço da unidade (binária) dos gêneros são a transfobia e a homofobia ${ }^{216}$. Esta última (e conforme as similaridades, a transfobia)

[...] tem sido utilizada para fazer referência a um conjunto de emoções, [de paixões] negativas (aversão, desprezo, ódio ou medo) em relação às homossexualidades. No entanto, [entender o conceito] assim implica limitar a compreensão do fenômeno e pensar o seu enfrentamento somente a partir de medidas voltadas a minimizar os efeitos de sentimentos e atitudes de 'indivíduos' ou de 'grupos homofóbicos', deixando de lado as instituições sociais que nada teriam a ver com isso. (PRADO, 2010, p. 7)

Prado desmascara o pretenso desconhecimento ou o não reconhecimento das instituições como espaços de produção, de reprodução e de atualização de dispositivos que tornam e tomam a heterossexualidade como a única possibilidade legítima da expressão sexual e de gênero, naturalizando-a.

A naturalização da heterossexualidade, via heteronormatividade, alimenta uma lógica de desumanização do sujeito que se orienta por outras corporalidades e por sexualidades para além da heterossexual. Essa desumanização é encenada por uma aparente unidade corpórea/biológica, isto é, toma-se o sujeito anatômico, em seus recôncavos, identificando-o por sua existência física/material e não pelo (re)conhecimento que ele quer dar e traçar de si para si mesmo e para o mundo.

${ }^{216} \mathrm{O}$ romance autobiográfico de João W. Nery tem como subtítulo "Memórias de um transexual trinta anos depois" (grifo nosso). O primeiro impulso para a construção de nosso texto foi realizar uma espécie de arqueologia retórica da expressão heteronormatividade. Com o percurso da escrita, notamos que não poderíamos passar por cima de outra expressão construída contiguamente à heteronormatividade: homofobia. Percebemos então que o narrador de uma Viagem solitária se resguardava e lutava contra investidas transfóbicas e não homofóbicas. Optamos, assim, para o espaço deste texto, por reconhecer a transfobia com características similares às da homofobia. 
No capítulo 2, Casa da infância, de Viagem solitária, o narrador conta:

Geralmente, crianças adoram ganhar roupas novas nos dias de festa. Entrava em pânico quando mamãe nos carregava para a costureira. Relutava. A única coisa que conseguia reivindicar era que, pelo menos, o vestido tivesse gravata e bolsos. Mamãe não entendia ou fingia não entender. (NERY, 2011, p. 32)

A mãe do narrador não entende ou finge não entender $\mathrm{o}$ sofrimento do/a filho/a. Por outro lado, ela não tem consciência de que está reduzindo João/Joana a um ser meramente biológico. Segundo Giorgio Agamben (2010) no ensaio "A identidade sem pessoa", a presença do sujeito no mundo é dada não somente como materialidade verificável nos espaços institucionalizados, mas sobretudo pelo (re)conhecimento que os outros sujeitos têm dele a partir de premissas políticas, éticas, de gênero, culturais e linguísticas e que ele mesmo tem de si. São essas condições que tornam o ser um sujeito que habita o mundo e que é capaz de mudar a si mesmo e ao seu redor; se não fosse assim, o sujeito seria tão somente um ser-vivo, um ser-que-vive, vivendo uma "[...] vida nua, um dado puramente biológico". (AGAMBEN, 2010, p. 66)

Que tipo de identidade se pode construir sobre dados meramente biológicos? Decerto que não uma identidade pessoal, que estava ligada ao reconhecimento dos outros membros do grupo social e, com este, à capacidade por parte do indivíduo de assumir a máscara social sem, no entanto, se reduzir a ela. Se a minha identidade é agora determinada em última análise por factos biológicos, que não dependem de maneira alguma da minha vontade e sobre os quais não tenho qualquer domínio, torna-se problemática a construção de qualquer coisa como uma ética pessoal. (AGAMBEN, 2010, p. 67)

As máscaras sociais são construídas retoricamente pela invenção, ela que alicerça o "edifício retórico", e a pedra fundamental dessa edificação é a quaestio/a questão, ou seja, o tema em torno do qual os argumentos gravitam, sofrendo os mais variados sismos, estando sujeitos 
A invenção da heteronormatividade: um romance autobiográfico | 491

às mais variadas configurações segundo os objetivos de quem profere os discursos ${ }^{217}$.

Na Retórica a Alexandre, obra atribuída a Aristóteles ${ }^{218}$ (2012, p. 43), lemos que os discursos públicos (deliberativo, epidíctico e forense) se subdividem em sete espécies: persuasão, dissuasão, louvor, vituperação, acusação, defesa e investigação, podendo aparecer isoladas ou relacionadas. De modo geral, a maioria dos manuais de retórica e textos correlatos destacam a persuasão como a espécie preponderante, vez que as demais funcionam como reforço persuasivo, agindo por negação, sedução, deboche, comoção e inquirição.

Segue-se que, selecionada a quaestio, o tema do discurso, e tendo em mente a espécie discursiva em jogo, a invenção - mais a disposição/a narração, a elocução/o estilo, a ação e a memória -, como constructo do "edifício retórico", tem por função articular o éthos, o páthos e o lógos. Essas três instâncias são os componentes básicos da unidade retórica.

$\mathrm{O}$ éthos caracteriza-se como atributo daquele que profere o discurso/o orador, representando, de maneira geral, um sujeito com quem o público deve ser identificar. Se para chegar ao efeito persuasivo, é preciso demonstrar que as coisas sobre as quais se disserta são justas, legais, apropriadas, honrosas, prazerosas e exequíveis (ARISTÓTELES,

217 O conceito de discurso é um lugar cediço e disputado nos estudos de linguagem. Portanto, estabelecemos que doravante o tomaremos a partir do verbete "discursivo" do Dicionário de Filosofia, de Nicola Abagagnano (2012, p. 339): "Esse adjetivo corresponde ao sentido da palavra grega dianóia (v.) porque designa o procedimento racional que avança inferindo conclusões de premissas, ou seja, através, de enunciados negativos ou afirmativos sucessivos e concatenados" (o grifo é nosso).

${ }^{218}$ Vale deixar o alerta sobre a origem e a autoria de mais essa obra atribuída a Aristóteles, como referido por Bini (2012, p. 7): "Como de costume, os helenistas dividem-se quanto à sua origem e sua verdadeira autoria. [...] Sem entrar no mérito dessa polêmica de eruditos, de nossa parte, se não afirmamos ser a Retórica a Aristóteles pura e simplesmente um apócrifo, ainda que competentemente escrito, classificamo-la como um texto suspeito. [...] [seu] teor, assim como o tipo de tratamento do tema, apontam, na verdade, muito mais para a autoria de um sofista, o que, equivale dizer, precisamente para a prática retórica que Aristóteles não aceitava e combatia”. 
2012, p. 44), isso passa necessariamente pela representação ${ }^{219}$ que o orador constrói de si mesmo perante o público/a audiência. Assim, não somente as coisas exortadas devem ter essas características, mas também e sobretudo - o orador deve ser: justo, estando atento aos costumes situados historicamente; primar pela legalidade, agindo segundo a legislação pertinente ao seu tempo e lugar; honroso, gozando de boa reputação; prazeroso ${ }^{220}$, feliz; e demonstrar que ele é capaz de executar ou de fazer executar bem aquilo que defende.

Estando o éthos precipuamente ligado ao orador, o páthos é a fonte das indagações, das dúvidas, emanando do público/da audiência, movida que é por seus afetos ou pelos afetos que crê ter em si e que crê representá-la. Acontece que

a paixão, ao contrário das emoções, não diferencia mais entre o problema posto do exterior e a resposta subjetiva. A indiferenciação absorve a individualidade da pessoa, e não é portanto seguro que esta esteja acessível a uma argumentação que explicite, em particular, o que está sendo questionado, ao que passo que uma retórica aplicada ao resolutório se voltará preferencialmente ao sentido da paixão como efeito. [...]

A cegueira passional não estabelece diferença entre o que pertence à esfera da pergunta e o que se experimenta em resposta a essa pergunta [...] A paixão [então] transfere a problemática para o plano da resposta; [...]. (MEYER, 2007, p. 37)

219 Pensamos, aqui, a representação como jogo de linguagem, como sugerido por Wittgenstein em suas Investigações filosóficas, levando também em consideração que: "(Mentir é um jogo de linguagem que deve ser aprendido como qualquer outro.) [...] 'Não posso me representar o contrário' naturalmente não significa aqui: minha força de representação não é suficiente. Nós nos defendemos com estas palavras contra aquilo que, por sua forma, simula uma proposição empírica, mas é na verdade uma frase gramatical”. (WITTGENSTEIN, 1999, p. 99)

${ }^{220} \mathrm{Na}$ tradução utilizada da Retórica a Alexandre - que não é bilíngue -, a expressão "prazer" parece contígua a uma noção de felicidade ligada à utilidade de nossas ações no mundo. 
A invenção da heteronormatividade: um romance autobiográfico | 493

Sendo assim, postulamos que são os discursos institucionais, alicerçados sobretudo em práticas culturais, que alimentam a transfobia e a homofobia e as reforçam, por meio da criação da heteronormatividade como dispositivo retórico. Isso acontece, porque

a paixão é retórica por enterrar as questões nas respostas que fazem crer que elas estão resolvidas. É por isso que lidar com as paixões é sempre útil, retoricamente falando, ao passo que a argumentação, que põe explicitamente as questões sobre a mesa, faz mais apelo à razão do que à paixão. (MEYER, 2007, p. 38)

Para tentar escapar às armadilhas do éthos e do páthos, nos modelos discursivos, há uma razão, o lógos, que completa a unidade retórica.

O lógos deve poder expressar as perguntas e as respostas preservando sua diferença. É preciso cessar de considerar a proposição e o julgamento como a unidade do pensamento e do discurso. Eles nunca passam de respostas, e em razão disso rementem às questões que, ao resolverem, aparentemente fazem desaparecer. (MEYER, 2007, p. 40. O itálico é do autor)

A grande celeuma diz respeito à dimensão que as respostas do orador oferecem ao público/à audiência: elas simulam dar liberdade ao público/à audiência para assumir uma determinada postura que, no mais das vezes, coincide com a de quem profere o discurso. De modo cíclico, retornamos ao éthos, ainda que, segundo Meyer (2007, p. 40), “[...] toda resposta encontra sua liberdade em relação à questão que a gerou, e ela pode portanto remeter a outras questões".

A paixão, o páthos (i)mobiliza o público/a audiência para aceitar uma tese, comunicando uma diferença que é de quem profere o discurso e, por obra da invenção retórica, torna-se uma diferença extensível aos demais sujeitos, obscurecendo e sufocando a problematização em torno da tese, que jaz esquecida.

No capítulo 9 de Viagem solitária, intitulado Mercedes, o narrador escreve sobre a paixão por Mercedes, que durou seis anos e o ensinou a enfrentar situações que colocavam em risco sua "segurança": 
Andar vestido de homem na rua fazia com que me sentisse muito bem. O desagradável era parecer um garotão imberbe, com uma voz de taquara rachada. Comecei a desenvolver uma observação bem apurada e minuciosa dos detalhes do comportamento social masculino: gesticulação, hábitos, cacoetes, maneirismos. Andar com a mão direita metida na abertura da camisa, na altura do peito, era um gesto descompromissado e bem característico da conduta dos homens. Servia-me como um dissimulador. (NERY, 2011, p. 81. Grifos nossos)

A invenção da heteronormatividade, sendo constituída a partir de evidências ("comportamento social masculino") e de aparências ("gesticulação, hábitos, cacoetes, maneirismos") que se imiscuem/são incutidas dissimuladamente no público/na assistência para a boa recepção/o convencimento acerca de algo ("me sentisse muito bem" ao "andar vestido de homem na rua"), cria no narrador o desejo, na cena de rua, de parecer homem, fazendo-o entrar em estado de prontidão e como que se preparando para a representação de um papel.

Os maneirismos masculinos do narrador dissimulavam algo de feminino em seu modo de ser, o que o colocava a salvo da transfobia. Segundo Foster (2001, p. 52), tratando da homofobia, ela

[...] involucra la utilización de la violencia, lo mismo psicológica que física para imponer la fidelidad al heterosexismo compulsivo y castigar cualquier gesto que se pueda considerar una falta de fidelidad al mismo.

A violência imposta pela homofobia é de monta semelhante à que se impõe pela transfobia, pois, retornando à proposição de Agamben (2010), o sujeito se debate contra a possibilidade constante de viver uma "vida nua".

Por força do tempo e da tradição, uma invenção retórica se torna, ela própria, modelo para invenções subsequentes. Aqueles nas mãos de quem está o poder político (não necessariamente partidário), socioeconômico e cultural fundam uma invenção, passando a usá-la como instrumento persuasivo, a fim de dissimular o processo manipulativo de construção das normas em sociedade. No caso de Viagem solitária, não é somente o querer parecer homem que expõe as invenções retóricas. Nery (2011, p. 22) dirigiu um táxi por um ano e meio pelas ruas do Rio de 
A invenção da heteronormatividade: um romance autobiográfico | 495 Janeiro enquanto cursava a faculdade de Psicologia. Em uma das corridas, o narrador carregou um passageiro cuja figura lhe pareceu "insólita":

A camisa era de um tecido feito seda, com estamparia havaiana. As calças brancas, assim como os sapatos e as meias. O cabelo, curto e engomado. As unhas, envernizadas, e as do dedo mínimo enormes. O tipo extravasava vaidade por todos os poros. O bigodinho bem aparado, artisticamente moldado em cima da boca quase sem lábios. (NERY, 2011, p. 119-120)

Há, no próprio universo dos homens cisgêneros, elementos que os distinguem em espécies, como podemos ler no excerto acima. O recurso utilizado pelo narrador na descrição do passageiro corresponde à percursio, a percursão, estratégia retórica que "[...] é uma acumulação de carácter enumerante e coordenante de objectos, ainda que cada um destes tivesse merecido pròpriamente um tratamento pormenorizado" (LAUSBERG, 1993, p. 243). Esse recurso parece objetivar, dentro do texto de Nery, o enfraquecimento do efeito do discurso heteronormativo em sua "viagem", começando pela descrição das vestimentas do sujeito, chegando ao seu comportamento:

Era daqueles a quem não se precisa ajudar para começar qualquer tipo de conversa. $O$ assunto que escolheu não se relacionava nem com ele, nem com os outros mais comigo. - O que faz além de trabalhar aqui? Estuda? Namora? Come as menininhas que encontra? Vamos lá, rapaz, desembucha que quero saber. (NERY, 2011, p.120)

Se, num primeiro momento, apresentamos o desejo do narrador de querer parecer homem, por outro lado, ele tem consciência de que há certos homens com quem não quer parecer, ainda que isso nos seja dito de maneira dissimulada. Mesmo para se (trans)formar, o sujeito obedece a algumas conveniências afeitas aos costumes de parecer e de ser homem e que passam pelas vestimentas, pela dignidade e pela consistência da orientação para esse gênero.

A pergunta "que espécie de homem eu quero ser?" subjaz no discurso do narrador de Viagem solitária como um modo de entendermos que se um dos propósitos da heteronormatividade é afirmar a legitimidade universal e inquestionável de uma ideologia heterossexual, 
por outro lado, se de fato fosse assim, a homofobia não seria necessária, uma vez que, se há uma norma inexorável, por que é preciso negá-la e combatê-la?

\section{REFERÊNCIAS}

ABBAGnANO, N. Dicionário de Filosofia. Trad. Ivone Castilho Benedetti. 6ed. São Paulo: Martins Fontes.

AGAMBEN, G. Identidade sem Pessoa. In: . Nudez. Trad. Miguel Serras Pereira. Lisboa: Relógio D’Água, 2010.

ARISTÓTELES. Arte retórica. Trad. Antônio Pinto de Carvalho. Rio de Janeiro: Tecnoprint, [s.d.].

ARISTÓTELES. Retórica a Alexandre. Trad. Edson Bini. São Paulo: EDIPRO, 2012. (Série Clássicos EDIPRO).

COLlinG, L. O que perdemos com os preconceitos? Cult - Revista Brasileira de Cultura, ano 18, pp. 22-25, jan. 2015.

DAMASCENO, Í. Uma carta para João W. Nery: precisamos te pedir esperança. Disponível em: <https://www.metropoles.com/colunasblogs/vozes-lgbt/uma-carta-para-joao-w-nery-precisamos-te-pediresperanca>. Acesso em 13 ago. 2019.

FOSTER, D. W. Consideraciones sobre el estudio de la heteronormatividad en la literatura latinoamericana. Letras, Santa Maria, PPGL - UFSM, n. 22, pp. 49-53, jan./jun. 2001.

LAUSBERG, H. Elementos de retórica literária. Trad. R. M. Rosado Fernandes. 4ed. Lisboa: Calouste Gulbenkian, 1993.

MEYER, M. A retórica. Trad. Marly N. Peres. São Paulo: Ática, 2007. (Série Essencial).

NERY, J. W. Viagem solitária: memórias de um transexual trinta anos depois. São Paulo: Leya, 2011.

PRADO, M. A. M. Homofobia. Muitos fenômenos sob o mesmo nome. In: BORILLO, D. Homofobia: história e crítica de um preconceito. Trad. Guilherme João de Freitas Teixeira. Belo Horizonte: Autêntica, 2010. (Ensaio Geral; 1).

SPINA, S. Regras gerais. In: Introdução à poética clássica. 2ed. São Paulo: Martins Fontes, 1995. (Ensino Superior).

TODOROV, T. El viaje y su relato. In: _____. Las morales de la historia. Trad. Marta Bertran Alcázar. Barcelona: Paidós, 1993. (Paidós Básica). 
A invenção da heteronormatividade: um romance autobiográfico | 497

WITTGENSTEIN, L. Investigações filosóficas. Trad. José Carlos Bruni. São Paulo: Nova Cultural, 1999. (Os Pensadores).

Recebido em: 16/08/2019

Aceito em: 14/09/2019 